\title{
8
}
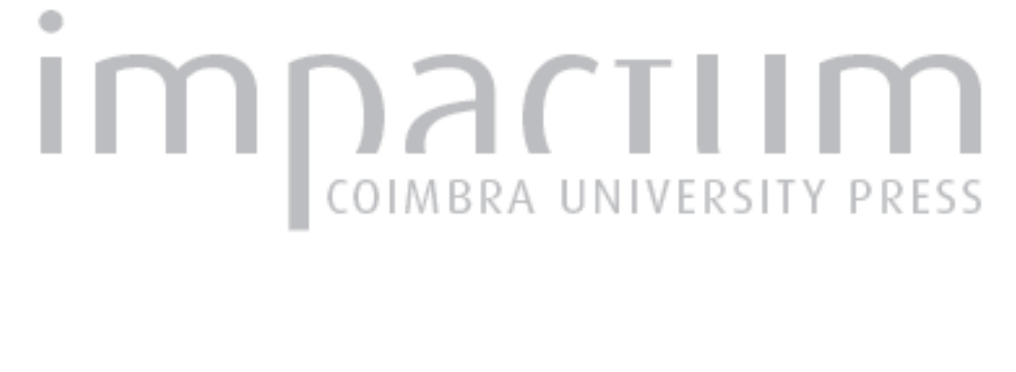

\section{O estudo dos riscos e das crises discutido em reuniões internacionais}

\section{Autor(es): Rebelo, Fernando}

Publicado por: Associação Portuguesa de Riscos, Prevenção e Segurança

URL persistente:

URI:http://hdl.handle.net/10316.2/40155

DOI:

DOI:https://doi.org/10.14195/1647-7723_4_13

Accessed : $\quad$ 26-Apr-2023 11:36:32

A navegação consulta e descarregamento dos títulos inseridos nas Bibliotecas Digitais UC Digitalis, UC Pombalina e UC Impactum, pressupõem a aceitação plena e sem reservas dos Termos e Condições de Uso destas Bibliotecas Digitais, disponíveis em https://digitalis.uc.pt/pt-pt/termos.

Conforme exposto nos referidos Termos e Condições de Uso, o descarregamento de títulos de acesso restrito requer uma licença válida de autorização devendo o utilizador aceder ao(s) documento(s) a partir de um endereço de IP da instituição detentora da supramencionada licença.

Ao utilizador é apenas permitido o descarregamento para uso pessoal, pelo que o emprego do(s) título(s) descarregado(s) para outro fim, designadamente comercial, carece de autorização do respetivo autor ou editor da obra.

Na medida em que todas as obras da UC Digitalis se encontram protegidas pelo Código do Direito de Autor e Direitos Conexos e demais legislação aplicável, toda a cópia, parcial ou total, deste documento, nos casos em que é legalmente admitida, deverá conter ou fazer-se acompanhar por este aviso.

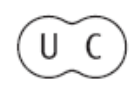




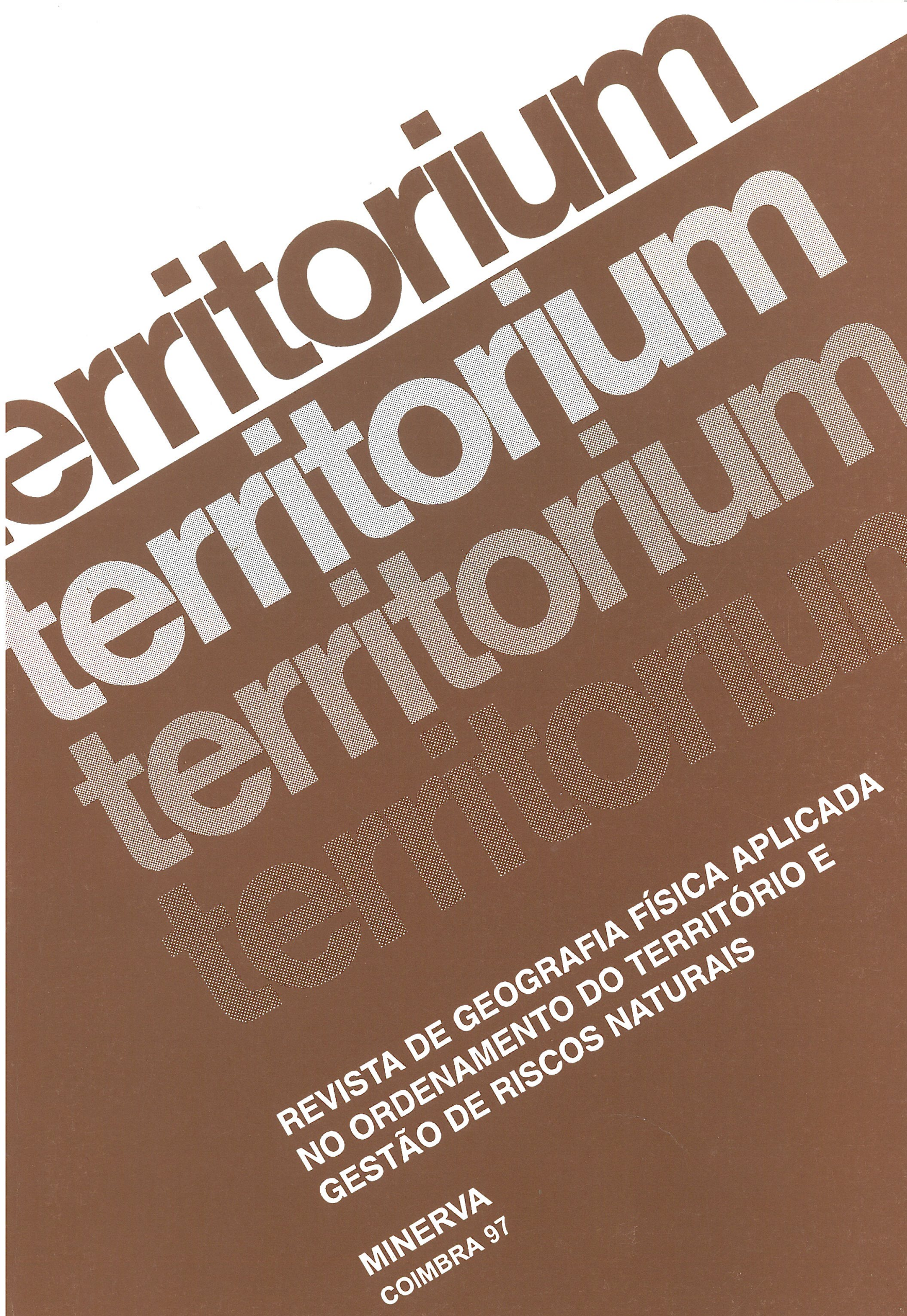




\title{
O estudo dos riscos e das crises discutido em reuniões internacionais
}

\author{
Fernando Rebelo
}

1. Por motivos vários, só muito recentemente, sob otítulo Risque, Nature et Société (Paris, Publications de la Sorbonne, 1996, 252 p.), foram publicadas as Actas do Seminário "Delphes I", organizado pelo Centro Europeu de Coordenação, Investigação e Documentação em Ciências Sociais.

Como escreveram os editores (LUCIEN FAUGÈRES, Professor de Geografia Física da Universidade de Paris I, e CHRISTIANE VILLAIN-GANDOSSI, Investigadora de História do CNRS e da UNESCO), numa introdução muito breve a que chamaram "Théories et pratiques interdisciplinaires appliquées au domaine du risque", o seminário de formação avançada realizado em Delfos, de 25 a 27 de Março de 1990, enquadrouse num tema geral intitulado "Interdisciplinaridade nas Ciências Sociais" e "representou uma nova etapa nas trocas internacionais e interdisciplinares desenvolvidas no seio do GEERC" (Grupo de Estudos Europeu sobre o Risco e a Crise). Um dos três encontros anteriores que estiveram na origem do GEERC, o de Saint-Valery-sur-Somme, já havia sido objecto de um livro de Actas importante: Le Risque et La Crise (Malta, Foundation for International Studies, 1990, 218 p.). Segundo os editores, a reunião de Delfos "devia permitir um aprofundamento da teoria do risco e da crise, cujo primeiro esboço tinha já sido feito em Saint-Valery-sur-Somme" e patenteado nos diversos trabalhos incluidos nesse livro. Os mesmos editores esperavam que em Delfos fosse possível "chegar a um acordo sobre o conteúdo a dar a alguns termos chave fornecendo as bases duma língua comum do risco e da crise; tratava-se igualmente de utilizar a análise dos acontecimentos e manifestações de riscos reais para fazer progredir a modelização dos procedimentos de tomada de decisão e de gestão das crises". Diziam ainda os editores que, "por outro lado, o esforço teórico devia ser contrabalançado e confortado por uma aplicação num domínio de risco preciso, interessando um espaço definido, caracterizando-se por impactos pesados e suscitando desde há alguns anos uma intensa actividade de investigação. $\mathrm{O}$ estudo de casos retido cobria o risco sísmico, principalmente sobre o território grego, e as dificuldades encontradas no estabelecimento de um método de previsão dos sismos, conhecido pelo nome de método VAN" (p. 11-12).

Por isso, neste livro recentemente posto à disposição dos leitores, as comunicações organizam-se em torno de duas partes - I, "Positions de recherche, methodologie" e II, "Etude de cas, la prévision des séismes (Grèce, Albanie)".
$\mathrm{Na}$ primeira parte, encontramos comunicações como a de LUCIEN FAUGËES, intitulada "Expériences sur la voie de conduites interdisciplinaires et transdisciplinaires concretes", e a de CHRISTIANE VILLAIN-GANDOSSI, "Méthodologies interdisciplinaires". Nesta última, permitimo-nos destacar a parte do parágrafo sobre "disciplina, interdisciplinaridade, transdisciplinaridade", quando, a Autora, depois de salientar que o carácter de multidisciplinaridade ou de pluridisciplinaridade "significa muitas vezes a reunião no mesmo lugar de especialistas que nada têm a dizer uns aos outros já que não têm linguagem comum", vai buscar um texto de Georges Gusdorf que merece ser conhecido: "O tema da interdisciplinaridade evoca uma figura espacial diferente. Não se trata somente de justaposição, mas de posição em comum. $\mathrm{O}$ interesse coloca-se nos confins e recortes mútuos entre as disciplinas; trata-se de um conhecimento nos limites instituindo entre os diversos ocupantes do espaço mental um regime de copropriedade que funda a possibilidade de um diálogo entre os interessados. Esta noção retoma a ideia da universitas scientiarum constitutiva da universidade tradicional" (p. 37).

"Sociology, risks and disasters" é o título da comunicação seguinte, da autoria de JAN BERTING, Professor de Sociologia da Universidade Erasmus, de Roterdão. Particularmente importante no que respeita à teoria, também se encontra aí, como exemplo de efeitos dos grandes desastres sobre as sociedades, um caso mundialmente conhecido de crise (as inundações da Holanda, em 1953, que devastaram largas áreas do sudoeste do país tendo causado uns 2000 mortos) e o modo como se processou a solução para que esse risco não volte a manifestar-se durante gerações.

GEORGES HADJICONSTANTINOU, então Professor de Economia da Universidade Aristóteles, de Salónica, apresentou uma comunicação intitulada "À la recherche d' une approche interdisciplinaire en Economie. L' ouverture à la complexité", na qual se debruçava sobre a complexidade da ciência moderna e na problemática do ensino dessa complexidade. $\mathrm{O}$ mesmo Autor, juntamente com o seu colega economista do Municípiode Salónica CHRISOSTOME KALOGIROU, apresentou, em seguida, uma outra comunicação bem mais prática - "Risques et pauvreté. Le cas de la région ouest de Thessalonique"; a pobreza, como o risco maior da região, é estudada a partir de vários índices de carácter sócio-económico, mas não deixa de ser relacionada com riscos de poluição ambiental e até com o risco sísmico tão importante na região. 
Outro Professor grego, do City College de Salónica, EVANGELOS DRYMBETAS debruçou-se sobre ' $L$ ' incertitude dans les phenomènes non linéaires. La théorie du chaos", enquanto GEORGES PAPACHRISTOU, também Professor de Economia da Universidade Aristóteles, de Salónica, falou da "Théorie économique du risque" confrontando, curiosamente, a teoria com a realidade em que "habitantes de um vale americano recusam participar num programa público de seguro contra inundações" e "habitantes duma região de forte actividade sísmica recusam pagar voluntariamente o custo do reforço anti-sísmico das suas construções" (p. 93). Como isto nos fez lembrar a recusa de muitos agricultores portugueses em fazer seguros de colheitas...

Publicada igualmente na primeira parte deste livro de Actas está a comunicação de JEAN-FRANÇOIS NOËL, Professor de Economia da Universidade de Paris I, "Economie et risque écologique"; trata de avaliação pelas preferências individuais, avaliação pelas preferências colectivas e avaliação pelas características físicas sendo no quadro desta última que afirma que "o fundamento desta nova aproximaçãoé o reconhecimento do carácter material, 'real', da economia" em que não pode haver "uma exclusão do ambiente do campo do económico" (p. 102). E culmina com uma referência aos "desafios contemporâneos", às "poluições globais" como as que levam à diminuição da camada de ozono ou ao aumento do efeito de estufa que constituem "desafios para a análise económica" (p. 105). Neste contexto, o Autor não podia deixar de falar em desenvolvimento sustentável, que, citando um trabalho da Comissão Mundial sobre o Ambiente e o Desenvolvimento, é "um processo de mudança no qual a exploração dos recursos, a escolha dos investimentos, a orientação do desenvolvimento técnico, assim como a mudança institucional são determinados em função das necessidades tanto actuais como futuras" (p. 106).

ZDENEK MADAR, Jurista, da Academia das Ciências de Praga, assina a última comunicação da primeira parte - "Problèmes d' environnement et interdisciplinarité". - onde salienta o caso das ciências jurídicas muito particularmente no que respeita ao "direito do ambiente" incitando juristas e economistas a utilizarem termose noções que possam ser entendidos pelos não especialistas.

Na segunda parte das Actas do Seminário de Delfos vêm os estudos de casos. Como vimos, o principal "caso" era o método de previsão de sismos chamado "método VAN". Por isso, a primeira comunicação corresponde a uma introdução sobre sismos, com uma certa particularização sobre os sismos na Grécia, e à apresentação do método nas suas linhas gerais - "La méthode VAN, exemple de 'greffe' scientifique", da autoria de JACQUES LABEYRIE, Director de Investigação do CNRS. Salienta-se a elevada sismicidade da Grécia através de alguns números; por exemplo, 28 sismos de magnitudes compreendidas entre 7 e 8 no séc. XX. Mas salienta-se, igualmente, quanto eles podem ser mortíferos; na China, em 28 de Julho de 1976, um sismo de magnitude 8 , seguido de uma réplica de magnitude 7,4 dezasseis horas mais tarde, terá causado perto de um milhão de mortos. As vulnerabilidades são diversas, mas números como estes assustam e justificam bem o trabalho científico sobre a previsão dos sismos levado a cabo pelos membros da equipa VAN - VAROTSOS, ALEXOPOULOS e NOMIKOS. Estes cientistas basearam-se na orientação de minúsculas impurezas dipolares existentes nas rochas quando submetidas às compressões que antecedem os sismos; nessas circunstâncias, haverá lugar a "miríades de impulsões que se propagam no solo (e sem dúvida também na atmosfera) e se integram sob a forma de impulsões de corrente detectáveis a grandes distâncias $(100 \mathrm{~km})$ se o terreno é condutor" (p. 129). Outros cientistas tinham já verificado que as rochas sob pressão emitem ondas electromagnéticas mesmo através da atmosfera (p. 130-131). Os cientistas gregos desta equipa prepararam e instalaram em vários pontos do seu território estações capazes de receberem os sinais de passagem das ondas electromagnéticas através das "impulsões eléctricas" que "apareciam entre dois eléctrodos colocados no solo a algumas dezenas de metros um do outro" (p. 131) e começaram a prever sismos com uma precisão que até ai ainda ninguém tinha conseguido.

O método VAN foi exposto com grande pormenor e com os resultados positivos de muitas previsões na comunicação seguinte - "Short term earthquake prediction from measurements of the electric field of the Earth" - por P. VAROTSOS, K. ALEXANDROPOULOS e M. LAZARIDOU.

JACQUES LABEYRIE apresenta depois algumas reflexões sobre as características científicas do método - "Nouvelles idées, nouvelle complexité" - e LUCIEN FAUGËRES debruça-se sobre a "Histoire de la méthode VAN" num texto que subintitula "Conflits, crises, blocages dans une entreprise d' innovation methodologique" e ao qual acrescenta uma nota datada de 1995 em que informa que depois de 1990 "a equipa VAN prosseguiu a sua vigilância sismológica mas com meios consideravelmente limitados em relação aos de que dispunha nos anos de 1985-1989" (p. 198).

Outros trabalhos foram ainda publicados neste livro de Actas. Assim, temos um da autoria de EDUARD SULSTAKOVA, "Earthquake hazard assessment in Albania", incluindo vários mapas relacionados com o tema, e dois de SIASI KOCIAJ, "Earthquake prognostics and prediction" e "Some 
aspects of seismic microzoning in Albania", onde, entre outros assuntos, o Autor se preocupa com a determinação do risco sísmico.

A conclusão do livro Risque, Nature et Société é escrita pelo Prof. LUCIEN FAUGĖRES e intitula-se "De Delphes I à Delphes II (1991 -1996). Activités et Projets du Groupe d'Études Européen sur le Risque et la Crise (GEERC)". Trata-se, ao mesmo tempo, de fazer um relatório e de lançar as linhas mestras para um futuro de trabalho sobre risco e crise em que também estamos envolvidos, como se pode ler na última página (p. 252) - "Desde o início do ano escolar de 1992, o programa EURISURBE tornou-se uma realidade, com o ensino ministrado em Paris, Roterdão e Coimbra (e Manchester a partir de 1994) a estudantes dos respectivos países. O sucesso da experiência foi sancionado pela criação de um Diploma de Estado francês (Diplôme d'Études Supérieures Spécialisées, DESS) 'Gestion Globale des Risques et des Crises', cujos ensinamentos estão abertos aos estudantes de vários países europeus e começaram em Setembro de 1993" (cfr. F. REBELO, "A Geografia Física e a Gestão de Riscos. Um exemplo de colaboração da Universidade de Coimbra com a Universidade de Paris I (Sorbonne)". Territorium, 1, 1994, p. 74-75).

2. Risques Naturels, Risques de Sociétés (Paris, Economica, 1996, 103 p.) é, também, uma obra relacionada com uma importante reunião internacional onde o estudo dos riscos e das crises foi o grande tema. Comodiz o director da publicação, Prof. ANTOINE S. BAILLY, da Universidade de Genebra, "esta obra foi concebida na sequência do Festival Internacional de Geografia sobre o tema 'Riscos naturais, riscos de sociedades' que se realizou em Saint-Dié-des-Vosges em 6, 7 e 8 de Outubro de 1995".

Não se trata, propriamente de um livro de Actas, mas de um trabalho colectivo em que os geógrafos são autores maioritários. O livro é constituido por nove Capítulos, uma Bibliografia e uma breve "Biografia dos Autores".

O primeiro Capítulo, da autoria de ANTOINE S. BAILLY intitula-se "Environnement, risques naturels, risques de sociétés" e funciona como introdução. Desde logo, fica claramente expresso que estamos perante "l'unité nouvelle de la Géographie"; na medida em que "um risco físico, tal como uma inundação ou uma erupção vulcânica, não é somente natural; o facto de se falar dele, de o estudar, ilustra a relação homem-meio, geografia humana-geografia física" (p. 1). Nas palavras seguintes e nos quadros que as acompanham nota-se uma influência forte da escola anglo-saxónica, mas a conclusão faz lembrar os tempos áureos da Geografia Aplicada - "pensar em riscos inexistentes num tempot, fazer experimentações sobre a base de catástrofes imaginárias para preparar as populações para os perigos, prever planos de riscos, eis os elementos da tomada de consciência social dos riscos na qual a geografia pode contribuir" (p. 5).

OLIVIER DOLLFUS e ROBERT D'ERCOLE escreveram o segundo Capítulo - "Les mémoires des catastrophes au service de la prévision et de la prévention des risques naturels". A lição das grandes catástrofes é analisada com grande pormenor e a interacção entre o acaso e a presença humana é salientada, tal como o facto de as mesmas causas não produzirem obrigatoriamente os mesmos efeitos e de pequenas causas poderem ter grandes consequências (p.9). Não podem deixar de destacar-se os numerosos exemplos de catástrofes apresentados pelos Autores que terminam por chamar a atenção para o facto de estarmos perante "um belo tema de geografia contemporânea: pondo em primeiro lugar a questão das localizações, o cruzamento da memória dos tempos dos homens e da memória dos tempos da natureza, faz apelo aos progressos das técnicas e das disciplinas mais diversas" (p. 18).

Mais clássico em termos de apresentação dos grandes tipos de riscos é JEAN-CLAUDE THOURET no Capítulo 3 - "Les phénomènes naturels: approche globale, bilan et méthodes de prévention"; revela-se, todavia, muito importante, graças aos numerosos casos concretos referidos.

O Capítulo 4 desce a um pormenor de grande interesse - "Les risques naturels sur les côtes: inondations, érosions et glissements"; é seu Autor ROLAND PASKOFF, Professor da Universidade Lumière de Lyon, nome sobejamente conhecido da Geografia dos Litorais, que, dois anos antes, tinha publicado um livro sobre a matéria (Côtes en Danger. Paris, Masson, 1993, 250 p.). Numa síntese brilhante, neste seu capítulo-comunicação, o Autor debruça-se sobre os efeitos das vagas excepcionais, bem como das erosões marinhas, referindo-se, ainda, a casos de deslizamentos costeiros, exemplificando sempre com casos concretos.

O Capítulo seguinte (5), "La gestion des risques urbains", da autoria de PATRICK PIGEON trata de riscos naturais, mas também de outros, como os riscos tecnológicos, que se podem manifestar nas cidades. Como não podia deixar de ser, o texto vale pela chamada de atenção para um tema extremamente importante, que tem originado muitos estudos em todo o mundo. A sua leitura traz, sem dúvida, à memória o recente livro de C. CHALINE e J. DUBOIS, La Ville et ses Dangers (Paris, Masson, 1994, 247 p.), aliás, citado no trabalho e incluido na Bibliografia final.

O Capítulo 6 é escrito por DENIS ECKERT, intitula-se "Risque social, risque naturel en Russie" e trata um pouco de todos os riscos que se podem encon- 
trar nesse grande país ou que num passado não muito longínquo se manifestaram no território da ex-URSS; desde sismos a alcoolismo, passando por Tchernobyl, os exemplos são abundantes e diversificados.

Os Capítulos 7e 8, respectivamente, "Vers l'explosion de la sphère financière" (CHRISTIAN PIERRET) e "Le risque nucléaire" (JACQUES ATTALI), cada um na sua especialidade, apresentam um interesse global, embora não se refiram às nossas preocupações imediatas.

Por fim, o Capítulo 9, da autoria de ANTOINE S. BAILLY, "Des sociétés qui se croyaient à l'abri" é a conclusão que se impunha para este livro sobre riscos que salienta acima de tudo os riscos naturais. E porquê? Porque, diz o Autor, "o risco natural é o menos dominado, como o ilustra esta obra: secas, inundações, tremores de terra, deslizamentos de terras, ciclones, erupções vulcânicas são ameaças conhecidas" (p. 89) e, acrescentamos nós, tantas vezes vividas nas sua manifestações catastróficas.

3. Sem serem promovidas por geógrafos, muitas outras reuniões internacionais sobre riscos se têm realizado pelo mundo. Na sua publicação periódica de carácter informativo, Risk Management, a Association de Genève vai-nos dando uma ideia disso. Entre elas, parece-nos importante destacar a que se realizou de 16 a 18 de Novembro de 1994, no Grande Anfiteatro da Sorbonne, e que foi patrocinada pelo Jornal Le Monde e pela Universidade de Paris I (Panthéon-Sorbonne). Intitulou-se CINDYNICS 94, $2 e$ Colloque International sur les Sciences du Danger.

Nas Actas deste Colóquio (Risque et Société. Paris, Presses du Louvre, 1994, 399 p.) salientam-se, antes de mais, os nomes, alguns bem conhecidos, de muitos investigadores de todas as áreas em que se pode falar de riscos. Alguns deles deixaram pequenos resumos das intervenções que fizeram, outros publicaram-nas.

Na "Editorial" (p. 2-3), PHILIPPE VESSERON, Presidente do Instituto Europeu de Cindínicas (IEC), dá um breve resumo do que foi o Colóquio em cada uma das suas cinco secções - os riscos e a sociedade, os riscos e a cidade, os riscos e a empresa, os riscos e o homem e os riscos e a cultura. Segue-se a apresentação do programa, já com a indicação dos nomes

\section{A Protecção Civil e o Ensino}

\section{Fernando Rebelo}

Educar para a Proteç̧ão Civil. Projectos para a área-escola actividades de complemento curricular é o título de um livro muito interessante assinado por ELISA VILA NOVA publicado pela Texto Editora (Lisboa, 1996, 159 p.). dos intervenientes.

Sob a designação de "os riscos e a sociedade" aparecem comunicações muito variadas. Destaquemos os resumos das de HAROUN TAZIEFF, "Les risques naturels" (p. 17-18), e de J.-Y. COUSTEAU, "La nature a horreur du risque" (p. 34). Na secção seguinte, "os riscos e a cidade", intervieram, entre outros, J.-L. DESCHANELS, "La maîtrise des risques dans la ville" (p. 52-56), C. COLLIN, "Les risques et la cité retour d'expériences" (p.58-71), LUCIENFAUGERES, "Cindynique urbaine" (p. 74-88), e IAN DOUGLAS, "Geophysical risks in the cities of SouthEast Asia" (p. 100-124). Nesta última comunicação há numerosos exemplos de manifestação de riscos naturais em áreas urbanas, tais como sismos, tsunamis, erupções vulcânicas, ciclones tropicais e inundações com eles relacionadas, mas também movimentações de terras, erosões e sedimentações, subsidências e problemas cársicos.

Na secção "os riscos e a empresa" foram apresentados muitos casos concretos de riscos tecnológicos e outros que se colocam às empresas, mas também se teorizou um pouco recorrendo a trabalhos de GEORGES-YVES KERVERN. Aliás, logo na primeira página do livro se fala de dois deles - L'Archipel $d u$ Danger (feito com PATRICK RUBISE - Paris, Economica, 1991,444 p.) e Latest Advances in Cindynics (Colloque du Management Centre Europe, Berlin, 1993).

Na secção "os riscos e o homem" houve, naturalmente, comunicações de cariz teorizante e comunicações de cariz prático, falando-se dos riscos inerentes à vida das crianças, como dos riscos de acidentes de automóvel.

Finalmente, no respeitante à secção "os riscos e a cultura" falou-se na formação inicial e na formação permanente no domínio dos riscos, no modo como fazê-la nos diferentes níveis, nas categorias profissionais a que deve primordialmente dirigir-se e na informação geral do público em matéria de riscos e de prevenção.

Risque et Société é, como vimos, um livro de Actas. No entanto, dado o tipo de matérias em causa e a maneira como algumas delas são tratadas, por vezes, parece um manual sobre riscos que pode ajudar uma vasta gama de profissionais.

Além de um Prefácio assinado pelo Gen. Cabral Couto, Presidente do Serviço Nacional de Protecção Civil (SNPC), a obra é constituida por seis capítulos e termina com "algumas informações úteis" e "referências bibliográficas". Tal como se pode ler no 